\title{
Analysis of China's Income Inequality from the Perspective of Opportunity Inequality
}

\author{
Zhengyan Li \\ International Business School Suzhou, Xi'an Jiaotong-Liverpool University, Suzhou, 215123, China \\ *Corresponding author. Email:zhengyan.li18@student.xjtlu.edu.cn
}

\begin{abstract}
While the economy is developing rapidly, the income inequality that exists in China has reached a level worthy of vigilance. In recent years, some studies have found that inequality of opportunity plays an important role in the formation of income inequality. Therefore, this article first conducts a systematic review of the literature that studies the relationship between income disparity and inequality of opportunity. Secondly, combined with history and official statistics, it explored the causes and evolution of China's income gap and inequality of opportunity. The study found that the current inequality of opportunity in China that will exacerbate income disparity can be summarized as unequal regional development, unequal access to education, and large household income gaps. Based on the in-depth analysis of the above three problems, this article proposes corresponding solutions in combination with the current social reality.
\end{abstract}

Keywords: Income inequality, inequality of opportunity, intergenerational mobility, countermeasures

\section{INTRODUCTION}

In the past three decades, China has experienced rapid economic development and has become the second largest economy in the world. However, it is worth noting that not all citizens have enjoyed the economic development dividends equally. At the same time as economic development, China's national income gap is increasing. Statistics show that China's Gini coefficient has risen from 0.317 in 1978 to 0.465 in 2019. China's income gap problem has become an important factor restricting social development and needs to arouse people's vigilance. However, the Gini coefficient also has its limitations in the indicative sense. This economic indicator can only simply reflect the basic situation of contemporary income distribution and ignores the intergenerational flow of income. In exploring the causes of income disparity, scholars found that income inequality should be dialectically divided into two parts. Part of income inequality stems from the individual's effort and choice, and it is the part that the individual needs to be responsible for. Studies have found that the existence of this inequality has a positive impact on economic growth and is worth encouraging [1]. The other part is determined by a series of objective environmental factors that the individual cannot determine or exert influence, such as the personal growth environment and the quality of education received. The latter is called inequality of opportunity. It is a kind of inequality that is truly important from the perspective of social justice and is considered to be the source of the widening gap between the rich and the poor. Eliminating inequality of opportunity in a country will help build a fairer society. It will also increase economic efficiency and promote economic development. The connection between inequality of opportunity and income disparity is a research theme that has emerged in the past two decades.

The income gap in China has its own particularities. It is related to the climate and resource endowments of various regions and is also affected by changes in social systems and productivity in different periods. This article will be based on past empirical papers that explored China's inequality of opportunity and income gap, combined with historical and relevant statistical data, to provide a more comprehensive and in-depth explanation of past research results. At the same time, in combination with the trends and characteristics of China's social development in recent years, more time-sensitive policy recommendations are put forward based on the results of past research. 


\section{LITERATURE REVIEW}

In the 1990s, research on the gap between the rich and the poor began to emerge in the West. Although early studies focused on the impact of regional financial development on income gaps, some of these studies have already reflected the thinking on inequality of opportunity. For example, Greenwood and Jovanovic pointed out in their book that in the early stage of regional financial development, different groups had unequal access to loans, and some groups needed to face more restrictions in enjoying financial services and this phenomenon aggravated income inequality [2].

The contemporary concept of equality of opportunity was systematically put forward by Roemer [3]. He stressed that the final result of individuals (income, health status, etc.) is the product of the joint action of individual efforts (career choice, years of education, etc.) and environmental factors beyond individual control (socio-economic status, growth environment, gender, etc.) [3]. A fair society should ensure that those who make the same efforts can get the same level of results, and there will be no differences due to different environmental factors [3]. Since then, the research on inequality of opportunity in income gap has developed rapidly. Bourguignon, Ferreira, and Menéndez combined the distribution of the hourly income of urban men in Brazil and the results of the 1996 Brazilian household survey, and found that race, place of birth, parent's education and father's occupation all contribute to individual income [4]. Their research also pointed out that exogenous environmental factors not only directly affect the individual's income, but also indirectly affect the individual's level of effort [4]. Ferreira and Gignoux conducted a study on six Latin American countries and found that nearly $25 \%-50 \%$ of the observed income inequality is caused by inequality of opportunity [5]. Among a series of exogenous environmental variables, the effects of variables related to family background are particularly significant [5]. In addition, the research of Ferreira and Gignoux also found that the inequality of opportunity within each country has obvious spatial distribution characteristics, and most people deprived of opportunities tend to be concentrated in a specific area, such as underdeveloped economies or chaotic management areas [5]. Marrero and Rodríguez studied the inequality of opportunity in European countries and found that the inequality of access to education has a strong correlation with overall inequality [6]. The study also found that in some high-welfare countries, higher levels of opportunity inequality coexist with lower levels of overall inequality [6]. Therefore, the in-depth analysis of the causes of inequality of opportunity in a specific country must be combined with the country's reality and cannot be simply replaced by empirical evidence from cross-country studies.
The research on the impact of inequality of opportunity on income inequality in China started relatively late, and most of the research adopted a relatively complete model framework developed in earlier Western studies. Zhang selected data from nine provinces in China between 1989 and 2006 to study the impact of inequality of opportunity on income inequality and the result shows that observable inequality of opportunity can explain more than half of the income inequality [7]. Compared with the results of earlier studies in the West, the effects of parents' income and occupation on inequality are still significant, but parents' education level has no significant effect on their children's future income [7]. Li and Lyu studied the impact of inequality of opportunity in the gap between the rich and the poor based on the 2008-2015 data from the China Comprehensive Social Survey, and proposed that among many environmental factors, education-related factors have the most significant impact, which can explain about $40 \%$ Impact caused by inequality of opportunity [8]. At the same time, Li and Lyu also pointed out that the problem of inequality of opportunity between urban and rural areas are still significant, but the degree of inequality of opportunity caused by geographical location is on a downward trend [8]. The inequality of opportunities faced by groups born in different ages is also different, and these differences can be largely attributed to changes in socio-economic conditions and the evolution of economic systems [9].

In general, empirical studies in almost all relevant fields recognize that two major types of factors, residential area, and family background, are the most important sources of inequality of opportunity. In addition, they all agree that the income of parents in the family background can influence the children's growth environment and affect their children's future income levels. In the study of a long-time span, changes in the social environment have also played an important role. However, the past research still has certain defects, mainly due to the following three reasons. One is that it is difficult to accurately separate the impact of objective environmental factors and personal effort factors. For example, an individual's living conditions may affect his efforts. However, this influence will eventually be absorbed by environmental factors in the research,and cause errors in the research results. Second, in the analysis, the effects of some environmental variables have been over-amplified. For example, parents' income not only means better material conditions, but also often affects the quality of education and residential area, but both influences are captured by family income. This is mainly due to the imperfect data set and too few exogenous environmental factors to choose from in the government statistical reports required for research. Third, the lack of data limits the space and time of research, which makes it impossible to describe and 
analyze the problem as a whole, and there is the possibility of underestimating the degree of income gap and inequality of opportunity.

\section{STATUS AND ANALYSIS}

\subsection{The Current Situation of Income Gap in China}

The income gap among Chinese residents has reached a considerable degree. NBSC statistics show that China's Gini coefficient has increased from 0.317 in 1978 to 0.465 in 2019. At the same time, China's rich and poor have clearly divided. According to the results of the National Bureau of Statistics in 2019, the per capita disposable income of $20 \%$ of high-income households in the country is more than ten times that of $20 \%$ of low-income households. The income gap of Chinese residents has obvious group characteristics, which are mainly reflected in differences between urban and rural areas, regional differences, and industry differences. China Statistical Yearbook 2020 shows that the ratio of per capita disposable income of urban residents to per capita disposable income of rural residents has gradually expanded from 2.57:1 in 1978 to $2.64: 1$ in 2019. Regional income gaps are obvious. The per capita disposable income of residents in the eastern region is significantly higher than that of residents in the northeast, central and western regions, and the per capita income of residents in coastal areas is higher than that in inland areas. The income gap between industries has been expanding in the past ten years, especially in the gap between the finance, real estate and Internet industries and other industries. At the same time, the income gap between monopoly and non-monopoly industries is also expanding.

\subsection{Causes for the Enlarging Income Gap in China}

\subsubsection{Regional factors}

From a historical and geographic perspective, China has recorded six large-scale southward migrations in history, which established the pattern of uneven population distribution in China's north and south. At the same time, the eastern region bordered by the $\mathrm{Hu}$ Huanyong line has a superior natural environment and good resource endowments, while the western region has a relatively harsh natural environment and is more difficult to develop. Historically, the degree of development in the east of China was much higher than that in the west. The foundation of China's regional income gap problem has been formed since ancient times. The history of the evolution of the income gap issue in New China began with the reform and opening up changing the original distribution system with egalitarianism as the guiding ideology, and the implementation of a parallel distribution system with multiple distribution methods. In the initial period of opening up, the Chinese government allowed the eastern region to take the lead in market-oriented reforms and implemented a series of preferential policies in the eastern region to attract foreign capital. As a result, the eastern coastal areas developed rapidly. When China fully opened up to the outside world in 1991, other regions could no longer match the eastern region in terms of infrastructure construction, capital, and technology. This situation has also led to a widening of the income gap between regions.

\subsubsection{Institutional factors}

China's income gap problem also has some institutional factors. In the early days of the founding of the People's Republic of China, the household registration system effectively ensured the stable development of society, but the restrictions on population movement and migration also delayed China's urbanization process to a certain extent. The rural population failed to equally enjoy the dividends brought about by economic development in the early stage of market reform, which led to the widening of the income gap between rural and urban residents. In the past ten years, this problem has been greatly improved through various administrative measures. However, China's current income distribution system still has some unreasonable aspects. These defects are mainly manifested in the low proportion of labor income in the initial distribution, a low minimum wage level, and a low tax burden for the wealthy in the redistribution.

\subsubsection{Policy factors}

The issue of income disparity among industries in China is influenced by policy factors. Industries such as telecommunications, electric power, and finance have long been under administrative protection and have obtained high monopoly profits, and the wages of related employees have been at a high level for a long time. However, it must be admitted that the government's institutional monopoly on industries related to people's livelihood is reasonable. This type of industry is closely related to the national economy and the people's livelihood. Relevant enterprises bear the responsibility of providing the people with basic and non-profit products and services that many private enterprises are unwilling to provide. The current problems are the immaturity of the regulatory mechanisms for these industries and the imperfect pricing methods.

\subsection{Inequality of Opportunities in China}

There is inequality of opportunity between China's economically developed regions and underdeveloped 
regions, which is particularly evident in the dual structure of urban and rural areas. The main observable inequality of opportunity is reflected in the unequal distribution of educational resources and unequal access to education. School infrastructure in economically developed areas is better and easier to attract high-quality teacher resources, while schools in economically underdeveloped areas not only have poor infrastructure and weak teachers, but there may even be people who cannot be covered by educational resources. The inequality of opportunity among different regions of China is gradually increasing. Initially, the inequality of opportunities in urban and rural areas may not be obvious. However, with the development of cities and industries, inequality in employment opportunities in urban and rural areas and the degree of inequality of opportunity in the corresponding welfare system of each area began to intensify, eventually resulting in income differences between urban and rural residents [7]. Combined with the idea of intergenerational transfer mentioned in the literature review, the income inequality of the previous generation is bound to affect the exogenous environment (such as material living conditions, education quality, etc.) of the next generation. In other words, a considerable part of the inequality of opportunity for a generation is caused by the income inequality of their parents. This effect will be reflected in the income gap of this generation and will continue to affect the next generation, eventually forming a cycle of inequality that demonstrates the Matthew effect. This may be a viable explanation for the growing inequality of opportunity among different regions in China. However, in recent years, the inequality of opportunities within economically developed regions has also begun to intensify, which is also more obvious in the education field. In some cities, private schools have replaced public schools in a dominant position. These schools have accumulated better teachers with higher wages and benefits. Children of families who are willing to pay higher tuition fees than public schools will get better quality of education than their peers. Generally, students in this type of school perform better in entrance examinations than students in ordinary schools. This fact strongly proves that income inequality can affect the inequality of opportunity for the next generation through intergenerational transfer. Moreover, with the rise of paid extracurricular education, even in developed regions, children from relatively less affluent families have difficulty obtaining fair competition opportunities.

\section{DISCUSSION}

In summary, to reduce the income gap caused by inequality of opportunity, the government needs to start with creating a more equal opportunity social environment and narrowing the current income gap. The practical problems that China is currently facing are mainly the unbalanced regional development, the unequal education opportunities of residents, and the current large family income gap.

The policy recommendations put forward in this article include the following three aspects. The first is to further promote the coordinated development of regions and promote the regions that become prosperous first to drive the development of other regions. The central and western regions can also try to strengthen economic exchanges with countries along the "Belt and Road", summarize their own advantages, actively participate in the international division of labor, and improve the level of regional industrial supply. Regarding the issue of unequal education opportunities for residents, it is first necessary to ensure the fairness of the current nine-year compulsory education. To bridge the gap between rural and urban education expenditures, the government should increase investment in rural education in fiscal expenditures. At the same time, the government should also introduce preferential policies to guide the flow of high-quality educational resources from developed areas to remote and backward areas. In terms of higher education, the government should consider the economic conditions of different regions. Less developed provinces should be allocated more educational resources than before, and therefore reduce the impact of uneven distribution of educational resources on those students in economically underdeveloped areas. Methods to narrow the income gap of residents can be divided into two categories: providing more equal employment opportunities and improving the distribution mechanism. Common employment discrimination includes gender discrimination, regional discrimination, and health discrimination. The government should build people's awareness of equal employment through propaganda. At the same time, it should improve China's anti-discrimination laws so that people whose employment opportunities have been violated can have ways to protect their rights. As far as the distribution mechanism is concerned, the government should regulate the order of personal income distribution and increase the intensity of distribution adjustment. At present, China's efforts to transfer the income of high-income groups are relatively small, and the relevant laws and regulations are not perfect. For low-income families, the government should gradually increase the minimum living security and minimum wage standards considering the current economic development situation. At the same time, the government should establish more effective distribution standards and strengthen the supervision of the distribution process and results. In order to achieve the objective of increasing the income level of low-income families, expanding the proportion of middle-income families, and effectively regulating the income of over-income families. 


\section{CONCLUSION}

First, this article conducts a more systematic review of the literature on the degree of inequality of opportunity in income disparity in the past and concludes that the objective environmental factors that can cause income inequality can be divided into two major categories: geographical and family background. At the same time, it is refined that the income inequality of the previous generation can lead to inequality of opportunity for the next generation through the transmission mechanism of intergenerational transfer. Then, starting from the development history of China's income gap, the author combines statistical data and observable social reality, comprehensively considering the impact of institutional evolution and policy changes, a more in-depth analysis of the effect of income gap on inequality of opportunity is carried out. It is concluded that the inequality of opportunity in the current income gap problem in China is mainly reflected in the uneven regional development, the unequal education level of residents, and the large family income gap. In response to the above issues, this article puts forward policy recommendations for promoting coordinated regional development, ensuring education fairness, eliminating occupational discrimination, and improving the distribution mechanism. Limited by the lack of statistical data and the inconsistent research methods, this article does not establish an empirical study to conduct a timelier research on the causes of the current inequality of opportunity in China's income gap. Future research should collect data containing more exogenous environmental factors, establish a more complete model, and explore changes in the relationship between inequality of opportunity and income disparity in a longer time span.

\section{ACKNOWLEDGMENT}

Firstly, I would like to show my deepest gratitude to Professor Martha L. Olney of the University of California, Berkeley, who have provided me with valuable guidance in every stage of the writing of this thesis. Further, I would like to thank my parents and all my friends for their encouragement and support. Without all their enlightening instruction and impressive kindness, I could not have completed my thesis.

\section{REFERENCES}

[1] World Bank. World Development Report 2006: equity and development[M]. The World Bank, 2005.

[2] Greenwood J, Jovanovic B. Financial development, growth, and the distribution of income[J]. Journal of political Economy, 1990, 98(5, Part 1): 1076-1107.
[3] Roemer J E. Equality of opportunity[M]. Harvard University Press, 1998.

[4] Bourguignon F, Ferreira F H G, Menéndez M. Inequality of opportunity in Brazil[J]. Review of income and Wealth, 2007, 53(4): 585-618.

[5] Ferreira F H G, Gignoux J. The measurement of inequality of opportunity: Theory and an application to Latin America[J]. Review of Income and Wealth, 2011, 57(4): 622-657.

[6] Marrero G A, Rodríguez J G. Inequality of opportunity in Europe[J]. Review of Income and Wealth, 2012, 58(4): 597-621.

[7] Yingqiang Zhang. Research on the Impact of Inequality of Opportunity on Income Gap in my country[D]. Beijing: Beijing Jiaotong University, 2010. DOI:10.7666/d.y1781764.

[8] Ying Li, Guangming Lyu. Research on the Sources and Channels of Inequality of Opportunity in China $[\mathrm{J}]$. China Industrial Economics, 2019(9):60-78.

[9] Yuanyuan Cai, Jiqiang Guo, Shulan Fei. Trends and Causes of Inequality of Income Opportunities in China:1989-2015[J]. Zhejiang Social Sciences,2020(10):13-24. 